\title{
Heroin-induced changes of CD34-positive rat thymus cells
}

\author{
Gentimi Fotini ${ }^{1}$, Perrea Despina ${ }^{2}$, Marinos Evangelos ${ }^{3}$, Konstandi Ourania ${ }^{1}$, \\ Katsorchis Theodoros ${ }^{1 *}$ \\ ${ }^{1}$ Department of Cell Biology and Biophysics, Faculty of Biology, National and Kapodistrian University of Athens, Athens, Greece; \\ ${ }^{*}$ Corresponding Author: tkatsor@biol.uoa.gr \\ ${ }^{2}$ Lab for Experimental Surgery and Surgical Research, Medical School, University of Athens, Athens, Greece \\ ${ }^{3}$ Lab of Histology and Embryology, Medical School, University of Athens, Athens, Greece
}

Received 30 March 2010; revised 5 May 2010; accepted 7 May 2010.

\begin{abstract}
Heroin is a well known opioid that causes alterations to the immune system of a number of investigated animals. Only a few studies have explored the effect of heroin on the lymphocytes maturation. Thymocyte progenitors originate from haematopoietic stem cells in the bone marrow. The immature T-cells express neither CD4 nor CD8, and are therefore classed as doublenegative (CD4 CD8 ${ }^{-}$) cells. CD34 glycoprotein is the only defined marker of the immature Tlymphocytes. In this study we have investigated the changes induced in CD34+ rat thymocytes after heroin administration by immunofluorescence in frozen rat thymus sections using the 4H11 monoclonal anti-CD34 antibody. There is a remarkable decrease in the number of CD34+ immature thymocytes when examined 1hour after last heroin injection and a small recover when examination took place 20 days after last injection. The above results suggest a major effect of heroin administration early in the maturation process of $T$ lymphocytes probably by increasing the apoptotic cell death and the negative consequences for the immune system responses.
\end{abstract}

Keywords: Heroin; Rat Thymus; CD34

\section{INTRODUCTION}

Thymocytes are the principal mediators of the sympathetic stimulation that coordinate the organism's acute responses to a large variety of stressors, including the administration of narcotic drugs like morphine, an alkaloid of opium, and its less stable derivative heroin, which is eventually biotransformed into morphine $[1,2]$.
Heroin binds a) to endorphin receptors throughout the body causing a feeling of euphoria along with a "relict" of pain and b) to receptors of neurons that travel from the spinal cord to the limbic system causing a feeling of pleasure. Chronic heroin users become physically dependent on the drug; their endogenous endorphin production decreases and develops severe tolerance and withdrawal symptoms. The immunomodulatory properties of clinically relevant opiates, like morphine, are well established [3-5]. For example, numerous animal studies demonstrate that acute or chronic exposure to morphine produces alterations in many measures of immune status including in vitro immune responses, like the formation of plaque-forming cells, lymphocyte proliferation, cytokine production, and natural killer (NK) cell activity [3-6], and in vivo immune responses, like antibody production, graft-versus-host reactions, and contact hypersensitivity responses [7-9]. Previous studies have shown that some of heroin's immunomodulatory effects are similar to those produced by morphine, but some are unique. More specifically, both morphine and heroin produce a decrease in the proliferative response of splenic $\mathrm{T}$ and $\mathrm{B}$ cells, the cytotoxicity of NK cells, and the production of IFN-g by stimulated splenocytes.

However, heroin is approximately 10 times more potent than morphine in producing immune alterations in the spleen. Unlike morphine, the effect of heroin in ex vivo assays of splenic NK cell activity appears to result in part from a decrease in effect or NK cells in the spleen. Another effect unique to heroin is an alteration in the size of a granulocyte subpopulation in the spleen.

While previous investigations have explored the effects of heroin in the immune system responses only a few of them have studied its effects on lymphocytes maturation and cell death. It is well known that the thymus represents the major site of $\mathrm{T}$ lymphocyte maturation [1]. Different steps of thymocyte differentiation have been identified on the basis of both phenotypic and func- 
tional criteria $[1,10]$. The study of human thymic $\mathrm{T}$ cell progenitors has been hampered by the lack of markers as well as differentiation assays that unequivocally define these cells, although there is consensus that the most immature human thymocytes lack CD3, CD4, and CD8 $[8,9,11,12]$. The only well-defined marker expressed by a fraction of immature thymocytes is represented by the non lineage-specific CD34 [7] a 120-kD cell surface antigen that is expressed on pluripotent hematopoietic stem [13-15] cells and on precursors that are committed to several hematopoietic lineages, including the B [16], myeloid, and erythroid lineages $[13,14]$. Studies have shown that thymic CD34+ cells have a very limited myeloid differentiation capacity and differentiate in vitro mostly into CD1a+-derived but not CD14+-derived dendritic cells (DC).

In this study we have investigated the effects of heroin administration in CD34+ immature rat T-cell lympocytes using the 4H11 monoclonal anti-CD34 antibody in order to find some evidence on how-at very early stages- the lymphocytes maturation process is affected and what the consequences are for the rest of the immune system response. The results presented are in agreement with previous studies and extend our knowledge in relation to the apoptotic mechanisms in thymus after heroin administration. For the first time an immunohistochemical \& morphometrical analysis of thymus is made in order to quantitate cell apoptosis successfully, using CD34 as a specific marker.

\section{MATERIALS AND METHODS}

\subsection{Experimental Animals}

Thirty 2 weeks old male Wistar rats, weighing 50gr each, were housed in cages in a ventilated room with alternating light cycle, $12 \mathrm{~h}$ dark $/ 12 \mathrm{~h}$ light, at about $25^{\circ} \mathrm{C}$ and fed a standard chow diet and water ad libitum. They were divided in experimental groups $\mathrm{A}, \mathrm{B}$ and $\mathrm{C}$ containing ten animals per group.

\subsection{Protocol of Heroin Administration}

The experimental animals in groups $\mathrm{B}$ and $\mathrm{C}$ (ten animals each) received subcutaneous heroin injections daily, of increasing dosage for eighteen consecutive days, as follows: Starting dose was $1 \mathrm{mg}$ heroin $/ \mathrm{kg}$ animal body weight for days 1-3. The dose was doubled to 2,4 and 8 $\mathrm{mg}$ heroin/ $\mathrm{kg}$ per animal body weight, during days 4-6, 7-9 and 10-12, respectively. The dose was next increased to $12 \mathrm{mg}$ heroin $/ \mathrm{kg}$ animal body weight for days 13-15 and $16 \mathrm{mg} / \mathrm{kg}$ of animal body weight for days 16-18. The dose was next increased to $12 \mathrm{mg}$ heroin $/ \mathrm{kg}$ animal body weight for days $13-\mathrm{I} 5$ and $16 \mathrm{mg} / \mathrm{kg}$ of animal body weight for days 16-18 [5]. By analogy to the corre- sponding heroin volumes, the ten control rats (group A) received equivalent daily injections of isotonic saline for eighteen days. All heroin treated group B and all control rats (group A) were sacrificed $1 \mathrm{~h}$ after the last injection while group $\mathrm{C}$ (ten animals) rats where sacrificed 20 days after the last injection.

\subsection{Tissue Preparation and Immunofluorescense}

Immediately after dissection, the thymus tissues were immersed in $0.1 \mathrm{M}$ cacodylate buffer $\mathrm{pH} 7.4$ containing $4 \%$ paraformaldehyde and 5\% glutaraldehyde for $10 \mathrm{~min}$. They were washed in the same buffer supplemented with $25 \%$ sucrose for 5 to $10 \mathrm{~min}$, transferred to the same buffer supplemented with $2 \%$ glyoxylic acid and $25 \%$ sucrose for $15 \mathrm{~min}$ and quick-frozen in liquid nitrogen. Cryosectioning was performed at $-30^{\circ} \mathrm{C}$ by adjusting the microtome at 2 to $4 \mu \mathrm{m}$. Six and ten thymus sections per experimental and control animal group $\mathrm{A}$ and $\mathrm{B}$ respectively, were picked up on slides, mounted and fixed for $20 \mathrm{~min}$ in $3.5 \%$ formaldehyde sodium in PBS ( $\mathrm{pH} 7.2)$ and rinsed in PBS.

Tissue sections were exposed to CD34 antibodies (diluted 1:100) for $60 \mathrm{~min}$, rinsed in PBS and incubated with anti-mouse conjugated to fluorescein (1:300) for 30 min. All incubations were carried out at room temperature.

\subsection{Visualization}

The microscopic observation was carried out under a ZEISS AXIOPHOT microscope with excitation filter 13 (max. $400 \mathrm{~nm}$ ) and barrier filter 3 .

From each experimental animal biopsy, thirty photomicrographs were taken in total. Photographs 1-3 are representative. These were analyzed by a computer running the program Image-Pro plus (Media Cybernetics) Animal care and use was approved by the University ethics committee

\section{RESULTS}

Baseline distribution of transmembrane glycoprotein mucosaline (CD34) containing particles in thymocytes frontal sections from placebo and heroin treated rats, sacrificed 1 hour (group A and B) after the last injection with normal saline and heroin respectively as well as twenty [16] days (group C) after induce of heroin, was analyzed by histofluorescence using the anti-CD34 antibody detecting significant differences between the three groups. Fully T-cell comitted CD34+ immature thymocytes are normaly detected in untreated animals. Figure 1(a) shows a typical pattern of fluorescent glycoptotein signals classified as distinct grains and aggre- 
gates, under baseline conditions. Figures 1(b) and 1(c) show that there is a significant decrease in the number of the CD34+ glycoprotein signals 1 hour after heroin administration and a remarkable recovery 20 days after the last treatment. Despite the detected recovery, there is still a significant difference between the fluorescent signals corresponding to the CD34+ thymocytes detected in the untreated and the heroin administed animals.

Using the same program both the microphotographs and the pictures of the control sections and the ones after heroin administration, were analysed. The coverage of each field of vision of the aggregates and grains of Group A is $43 \%$ of their respective Group B is $29 \%$ and Group C is $37 \%$.

The histogram in Figure 2 resulted from the computer analysis of photographs of thymocytes stained with anti-CD34 antibody in sections, from heroin injected and naïve animals, summarizing the mean number of fluorescent particles, including grain (diameter less than 0.8 $\mu \mathrm{m})$ and aggregate (diameter greater than $1 \mu \mathrm{m}$ ) per optical field.

\section{DISCUSSION}

The fundamental role of the thymus in the development of an effective immune system is well established as well as the negative effects that the opioids such as heroin cause to the immune responses [12,17-19]. The results in the present study clearly demonstrate that heroin administration decreases the cellularity of rat thymus. This is in accordance with results from similar investigations in rat spleen and mice thymus. As deduced from

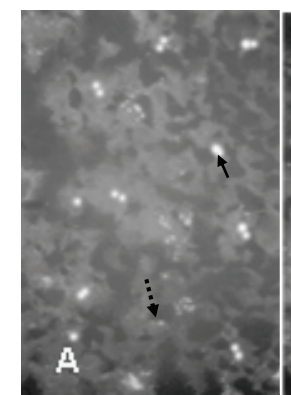

(a)

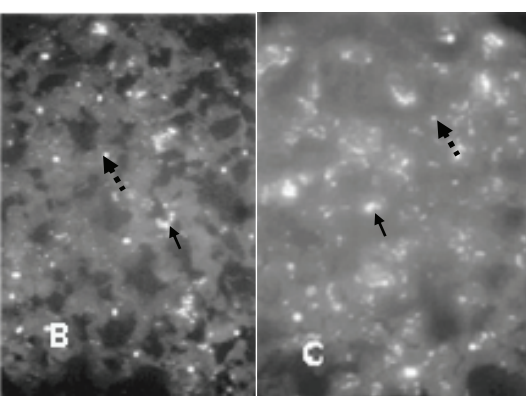

(b)

(c)
Figure 1. Fluorescent photomicrographs of rat thymus sections. The animals were sacrificed, one hour posi repetitive placebo or heroin administration. (a) Saline treated control group; (b) Heroin treated group sacrificed 1 hour after last drug injection. Fluorescent grains are indicated by arrowhead, aggregates by arrow; (c) Heroin treated group sacrificed twenty days after last drug injection. All magnifications were $(\times 800)$. Each photograph represented approximately one optical field from each group of animals. Straight arrows represent aggregates while dotted arrows represent grains.

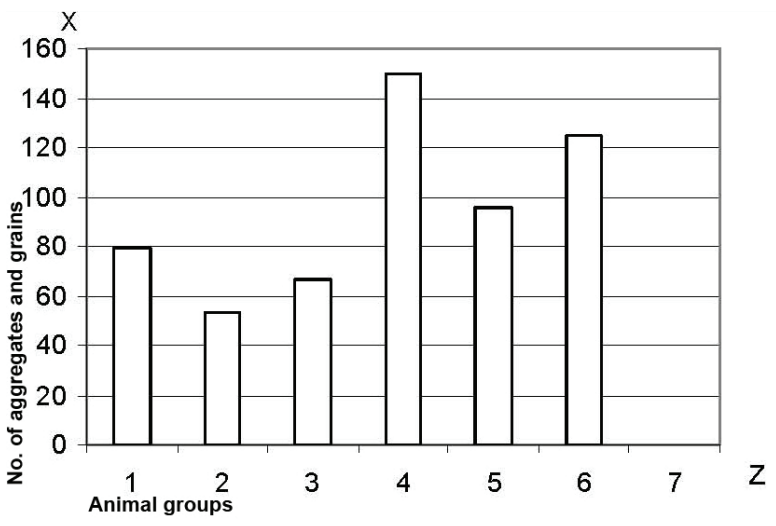

Figure. 2. The histogram resulted from the image analysis of the photomicrographs. $\mathrm{X}=$ Medium term of the number of aggregates and grains from 350 fields of observation. $Z=1-3$ the medium term of aggregates of the control group A (1), the group B, animals sacrificed one our after heroin administration (2) and the group $\mathrm{C}$, animals sacrificed 20 days after heroin administration (3). $Z=4-6$ the medium term of the grains of the control group $A$ (4), the group B, animals sacrificed one our after heroin administration (5) and the group C, animals sacrificed 20 days after heroin administration (6) $\mathrm{P}>0.05$.

literature, $\mathrm{CD} 34$ use as a specific marker was enough to reveal the effects of heroin. Although there is supporting evidence that adaptive mechanisms exist leading to tolerance prior to the development of abstinence to the drug since a small recovery take place after the discontinuance of heroin administration. These results are in accordance with previous studies performed in our laboratory investigating the baseline and heroin-suspended levels of the CD34 glycoprotein-containing particles including grain (diameter less than $0.8 \mu \mathrm{m}$ and aggregate (diameter greater than $1 \mu \mathrm{m}$ forms, in rat cell thymus immature cells [18]. Results from both studies show that heroin administration to heroin-tolerant or not rats causes formation of unusually large intracellular glycoprotein aggregates (diameter greater than $1 \mu \mathrm{m}$ ) in thymus cells and support a direct role for these formations in the modulation of biogenic glycoprotein bio-availability. The rational for our selection of the thymus in this study, was based on reports with tolerant nits indicating that opiates induce minimal changes in the glycoprotein pool of this thymus structure [6]. In previous studies, the parallel changes detected by electrophysiological immunocylochemical and autoradiographic techniques in thymus cells following opiate administration, suggest that biogenic glycoprotein interact directly with heroin and oilier narcotic analgesic drugs [20,21]. According to our findings it is proposed that the adaptation to drug exposure involves multiple homeostatic interactions, with sympathetic activation at the level of proteins reorganization and redistribution playing major roles in rat im- 
mune system.

It is well known that T-cells - a subset of lymphocytes play a major role in the immune response effectiveness. Their maturation process takes place in the thymus [22]. Different steps of thymocyte differentiation have been identified on the basis of both phenotypic and functional criteria [22,23]. Immature thymocytes have been negatively defined on the basis of the lack of surface expression of markers present at later stages of differentiation including CD3, TCR, CD4 and CD8 [24-28,29]. The only well-defined marker expressed by a fraction of immature thymocytes is represented by the non lineagespecific CD34 [28,30]. In spite of its expression on hematopoietic progenitors, the function of CD34 remains unresolved [31,32]. The 4H11 monoclonal antibody used in our studies reacts with human CD34, also known as mucosialin. According to our findings there is remarkable decrease of the CD34+ immature T lymphocytes after heroin administration suggesting that heroin can affect thymocytes survival or proliferation. These results in relation with recent investigations $[33,34]$ or in studies performed in our laboratory, strongly suggest an apoptotic role of heroin on immature T-cells. The growth- inhibitory or apoptosis-inducing effects of morphine in neurons and immunocytes are directly associated with morphine tolerance $[33,35]$ or receptor desensitization as assessed by a lack of morphine-stimulated GTPase activity at concentrations that inhibit tumor growth [16]. Drugs that prevented the development of morphine tolerance in rats also prevented cell death [33,34] and vice versa [33]. Recent investigations concerning the cellularity of another organ implicated in the immune process have shown similar results on the effects of heroin in splenic leucocytes [36]. Even a single injection of heroin produces a dose-dependent, naltrexone-reversible decrease in the total number of leukocytes in the rat spleen. The heroin-induced decrease in splenic leukocytes is not accompanied by a heroin induced increase in circulating leukocytes. Heroin does not increase the number of necrotic leukocytes in the spleen, but does increase the number of apoptotic leukocytes in the spleen. The heroin-induced increase in leukocyte apoptosis is clearly evident when splenocytes are isolated 1 or $3 \mathrm{~h}$ after injection, and the effect of heroin is maintained after $24 \mathrm{~h}$ of culture [36]. Similar findings have been shown in monocytes by inhibiting their response to activating stimuli after heroin administration [30,37].

In conclusion, in the present work a morphometrical study is made for the first time in order to show immunohistochemically that heroin administration to rats causes formation of unusually large intracellular aggregates with glycoprotein thymus cells, a finding supporting a direct role for these formations in the modulation of biogenic glycoprotein bio-availability and provide evidence of the apoptotic effects of heroin in immature thymocytes affecting their maturation and differentiation process.

\section{REFERENCES}

[1] Vizi, E.S., Orsó, E., Osipenko, O.N., Haskó, G. and Elenkov, I.J. (1995) Neurochemical, electrophysiological and immunocytochemical evidence for a noradrenergic link between the sympathetic nervous system and thymocytes, Neuroscience, 68(4), 1263-1276.

[2] Klous, M.G., Van den Brink, W., Van Ree, J.M. and Beijnen, J.H. (2005) Development of pharmaceutical heroin preparations for medical co-prescription to opioid dependent patients. Drug Alcohol Depend, 80(3), 283-295.

[3] Mahajan, S.D., Schwartz, S.A., Aalinkeel, R., Chawda, R.P., Sykes, D.E. and Nair, M.P. (2005) Morphine modulates chemokine gene regulation in normal human astrocytes. Clinical Immunology, 115(3), 323-332.

[4] Vallejo, R., de Leon-Casasola, O. and Benyamin, R. (2004) Opioid therapy and immunosuppression: A review American Journal of Therapeutics, 11(5), 354-365.

[5] Friedman, H. and Eisenstein, T.K. (2004) Neurological basis of drug dependence and its effects on the immune system. Journal of Neuroimmunology, 147(1-2), 106108.

[6] Clouet, D. and Rather, M. (1979) Catecholamine biosynthesis in brains of rats treated with morphine. Science, 168(3), 854-856.

[7] Lysle, D.T., Coussons, M.E., Watts, V.J., Bennett, E.H. and Dykstra, L.A. (1993) Morphine-induced alterations of immune status: Dose dependency, compartment specificity and antagonism by naltrexone. Journalof Pharmacology and Experimental Therapeutics, 265(3), 10711078.

[8] Bryant, H.U. and Roudebush, R.E. (1990) Suppressive effects of morphine pellet implants on in vivo parameters of immune function. Journalof Pharmacology and Experimental Therapeutics, 255(2), 410-414.

[9] Lockwood, L.L., Silbert, L.H., Fleshner, M., Laudenslager, M.L., Watkins, L.R. and Maier, S.F. (1994) MorphineInduced decreases in in vivo antibody responses. Brain, Behavior and Immunity, 8(1), 24-36.

[10] Haddad, R., Guimiot, F., Six, E., Jourquin, F., Setterblad, N., Kahn, E., Yagello, M., Schiffer, C., Andre-Schmutz, I., Cavazzana-Calvo, M., Gluckman, J.C., Delezoide, A.L., Pflumio, F. and Canque, B. (2006). Dynamics of thymus-colonizing cells during human development. Immunity, 24(2), 217-230.

[11] Nelson, C.J., How, T. and Lysle, D.T. (1999) Enhancement of the contact hypersensitivity reaction by acute morphine administration rat the elicitation phase. Clinical Immunology, 93(2), 176-183.

[12] Miller, J.F. (1996) Uncovering thymus functions. Perspectives in Biology and Medicine, 39(3), 338-352.

[13] Chang, S.J., Huang, T.S., Wang, K.L., Wang, T.Y., Yang, Y.C., Chang, M.D., Wu, Y.H. and Wang, H.W. (2008) Genetic network analysis of human CD34+ hematopoietic stem/precursor cells. Taiwanese Journal of Obstetrics and Gynecology, 47(4), 422-430 
[14] Porada, C.D., Harrison-Findik, D.D., Sanada, C., Valiente, V., Thain, D. and Simmons, P.J. (2008) AlmeidaPorada G, Zanjani ED. Development and characterization of a novel CD34 monoclonal antibody that identifies sheep hematopoietic stem/progenitor cells. Experimental Hematology, 36(12), 1739-1749

[15] Engelhardt, M., Lübbert, M. and Guo, Y. (2002) CD34(+) or CD34(-): Which is the more primitive? Leukemia, 16(9), 1603-1608.

[16] Tegeder, I., Grosch, S., Schmidtko, A., Haussler, A., Schmidt, H., Niederberger, E, Scholich, K. and Geisslinger, G. (2003) G protein-independent G(1) cell cycle block and apoptosis with morphine in adenocarcinoma cells: Involvement of p53 phosphorylation. Cancer Research, 63, 1846-1852.

[17] Quaglino, D. and Ronchetti, I.P. (2001) Cell death in the rat thymus: A minireview Apoptosis, 6(5), 389-401.

[18] Theodoros, K. and Burntenas, P. (1993). Immunofluorescence stady of astrocytes unter normal conditions and administration of heroin. Biosell, 17(2), 119-123.

[19] Tegeder, I. and Geisslinger, G. (2004) Opioids as modulators of cell death and survival-unraveling mechanisms and revealing new indications Pharmacological Reviews, 56(3), 351-369.

[20] Golstain, M., Freedman, L. and Backstrom, T. (1970) The inhibition of catecholamine biosynthesis by apomorphine. Journal of Pharmacy and Pharmacology, 22(9), 715717.

[21] Malev, H. and Pericid, D. (1987) Sex difference in the turnover of GABA in the rat substantia nigra. Journal of Neural Transmission, 70(3-4), 321-328.

[22] Haynes, B.F., Denning, S.M., Singer, K.H. and Kurtzberg, J. (1989) Ontogeny of cell precursors: A model for the initial stages of human T-cell development. Journal of Immunology Today, 10(3), 87.

[23] Spits, H.C. (1994) Early stages in human and mouse T-cell development. Current Opinion in Immunology, 6(2), 212

[24] Toribio, M.L., Martinez, A.C., Marcos, M.A.R., Marquez, C., Cabrero, E. and de la Hera, A. (1986) A role for T3+4-6-8-transitional thymocytes in the differentiation of mature and functional $\mathrm{T}$ cells from human prothymocytes. Proceedings of the National Academy of Sciences, 83, 6985.

[25] Toribio, M.L., de la Hera, A., Borst, J., Marcos, M.A.R., Marquez, C., Alonso, J.M., Barcena, A. and Martinez, A. (1988) Involvement of the interleukin 2 pathway in the rearrangement and expression of both alpha/beta and gamma/delta $\mathrm{T}$ cell receptor genes in human $\mathrm{T}$ cell precursors. Journal of Experimental Medicine, 168(6), 2231.

[26] Hari, T. and Spits, H. (1991) Clonal analysis of human CD4-CD8-CD3-thymocytes highly purified from postnatal thymus. Journal of Immunology, 146(7), 2116.

[27] Sanchez, M.J., Spits, H., Lanier, L.L. and Phillips, J.H.
(1993) Human natural killer cell committed thymocytes and their relation to the $\mathrm{T}$ cell lineage. Journal of Experimental Medicine, 178(6), 1857-1866.

[28] Galy, A., Barcena, A., Verma, S. and Spits, H. (1993) Precursors of CD3 + CD4 + CD8 + cells in the human thymus are defined by expression of CD34. Delineation of early events in human thymic development. Journal of Experimental Medicine, 178(2), 391-401.

[29] Poggi, A., Costa, P., Morelli, L., Cantoni, C., Pella, N., Spada, F., Biassoni, R., Nanni, L., Revello, V., Tomasello, E., Mingari, M.C., Moretta, A. and Moretta, L. (1996). Expression of human NKRP1A by CD34+ immature thymocytes: NKRP1A-mediated regulation of proliferation and cytolytic activity, European Journal of Immunology, 26(6), 1266-1272.

[30] Stoll-Keller, F., Schmitt, C., Thumann, C., Schmitt, M.P., Caussin, C. and Kirn, A. (1997) Effects of morphine on purified human blood monocytes. Modifications of properties involved in antiviral defences. International Journal of Immunopharmacology, 19(2), 95-100.

[31] Elknerová, K., Lacinová, Z., Soucek, J., Marinov, I. and Stöckbauer, P. (2007) Growth inhibitory effect of the antibody to hematopoietic stem cell antigen CD34 in leukemic cell lines. Neoplasma, 54(4), 311-320.

[32] Krauter, J., Hartl, M., Hambach, L., Kohlenberg, A. Gunsilius, E., Ganser, A. and Heil, G. (2001) Receptormediated endocytosis of CD34 on hematopoietic cells after stimulation with the monoclonal antibody antiHPCA-1, Journal of Hematotherapy and Stem Cell Research, 10(6), 863-871.

[33] Mao, J., Price, D.D. and Mayer, D.J. (1994) Thermal hyperalgesia in association with the development of morphine tolerance in rats: roles of excitatory amino acid receptors and protein kinase C. Journal of Neuroscience, 14(4), 2301-2312.

[34] Fecho, K., Maslonek, K.A., Coussons-Read, M.E., Dykstra, L.A. and Lysle, D.T. (1994) Macrophagederived nitric oxide is involved in the depressed concanavalin A responsiveness of splenic lymphocytes from rats administered morphine in vivo. Journal of Immunology, 152(12), 5845-5852.

[35] Wu, W.R., Zheng, J.W., Li, N.. Bai, H,Q., Zhang, K.R. and Li, Y. (1999) Immunosuppressive effects of dihydroetorphine, a potent narcotic analgesic, in dihydroetorphinedependent mice. European Journal of Pharmacology, 366(2-3), 61-69.

[36] Fecho, K. and Lysle, D.T. (2000) Heroin-induced alterations in leukocyte numbers and apoptosis in the rat spleen. Cellular Immunology, 202(2), 113-123.

[37] Sharp, B.M., McAllen, K., Gekker, G., Shahabi, N.A. and Peterson, P.K. (2001) Immunofluorescence detection of delta opioid receptors (DOR) on human peripheral blood CD4+ T cells and DOR-dependent suppression of HIV-1 expression. Journal of Immunology, 167(2), 1097-1102. 